\title{
Síndrome Hiper IgE: a propósito de tres casos clínicos
}

\author{
MARÍA TERESA TAGLE C. ${ }^{1}$, ALVARO MELYS G. ${ }^{1}$, ANGELA CASTILLO M. ${ }^{2}$, \\ XIMENA NORAMBUENA R. ${ }^{3}$, ARNOLDO QUEZADA L. ${ }^{3-4}$ \\ 1. Médico, Programa de Especialista en Inmunología, Facultad de Medicina, Universidad de Chile. \\ 2. Médico Inmunólogo Clínico, Servicio de Medicina, Hospital Carlos van Buren, Valparaíso. \\ 3. Pediatra Reumatólogo, Unidad Inmuno Reumatología, Hospital Dr. Exequiel González Cortés. \\ 4. Pediatra Inmunólogo Clínico, Departamento Pediatría Campus Sur, Facultad de Medicina Universidad de Chile.
}

\begin{abstract}
\section{Hyper IgE syndrome: three case reports}

Introduction: Autosomal dominant Hyper IgE syndrome (HIES-AD) is a primary immunodeficiency associated with connective tissue, skeletal, vascular and brain disorders. The pathogenesis of immune deficiency lies in an alteration of Th17 cells which explains the special susceptibility of these patients to $S$. aureus and Candida infections. Objective: To describe three children diagnosed with hyper IgE syndrome and conduct a study on the subject, with special focus on the dominant form of the disease. Case reports: 3 children with HIES-AD ( 2 males and one female) with eczema since birth, skin, ear, lung, and lymph node infections, and serum IgE levels over $2,000 \mathrm{IU} / \mathrm{ml}$ and eosinophilia values, treated with antibiotics and topically, and 7 year follow-up. Conclusions: It is a rare condition that requires a high index of suspicion and early management of infections. One of its main diagnoses is atopic syndrome with recurrent infections but both conditions differ in context, response and resolution against infections and lack of other phenotypic characteristics.
\end{abstract}

(Key words: Hyper IgE syndrome, autosomal dominant Hyper IgE syndrome, primary immunodeficiency, infection).

Rev Chil Pediatr 2014; 85 (3): 328-336

\section{RESUMEN}

Introducción: El síndrome Hiper IgE (SHIGE) autosómico dominante (SHIGE-AD) es una inmunodeficiencia primaria asociada a alteraciones del tejido conectivo, esqueléticas, cerebrales y vasculares. La patogénesis de la inmunodeficiencia reside en una alteración en la vía Th17 lo que explica la susceptibilidad especial de estos pacientes a infecciones por $S$. aureus y Candida. Objetivo: Describir tres niños diagnosticados como síndrome Hiper IgE y realizar una revisión sobre el tema, con especial foco en la forma dominante de la enfermedad. Casos clínicos: Se presentan 3 niños con SHIGE (2 varones), con rash eccematoso desde el período de recién

Recibido el 20 de noviembre de 2013, devuelto para corregir el 6 de enero de 2014, segunda versión 15 de enero de 2014 , tercera versión 27 de enero de 2014, aceptado para publicación el 2 de febrero de 2014.

Este trabajo cumple con los requisitos sobre consentimiento /asentimiento informado, comité de ética, financiamiento, estudios animales y sobre la ausencia de conflictos de intereses según corresponda.

Correspondencia a:

Arnoldo Quezada L.

E-mail: aquezada@med.uchile.cl 
nacido, infecciones cutáneas, óticas, pulmonares, ganglionares, con niveles de IgE sérica sobre $2.000 \mathrm{UI} / \mathrm{ml}$ y eosinofilia, tratados con antimicrobianos y tópicos, con seguimiento más de 7 años. Conclusiones: Es una entidad infrecuente, que requiere alto grado de sospecha y el manejo precoz de las infecciones. Uno de sus principales diagnósticos diferenciales está dado por el niño atópico con infecciones recurrentes pero difieren en el contexto, respuesta y resolución frente a las infecciones y la falta de las otras características fenotípicas. (Palabras clave: Síndrome Hiper IgE, Síndrome Híper IGE autosómico dominante, inmunodeficiencias primarias, infección).

Rev Chil Pediatr 2014; 85 (3): 328-336

\section{Abreviaturas}

$\begin{array}{ll}\mathrm{BCG} & =\text { Bacilo de Calmette Guerin. } \\ \mathrm{C} 3 & =\text { Complemento factor } 3 . \\ \mathrm{C} 4 & =\text { Complemento factor } 4 . \\ \mathrm{CD} & =\text { Cluster diferentiation. } \\ \mathrm{DOCK} & =\text { Dedicator of cytokinesis. } \\ \mathrm{DS} & =\text { Desviación estándar. } \\ \mathrm{IgA} & =\text { Inmunoglobulina A. } \\ \mathrm{IgG} & =\text { Inmunoglobulina G. } \\ \mathrm{IgE} & =\text { Inmunoglobulina } \mathrm{E} . \\ \mathrm{IgM} & =\text { Inmunoglobulina M. } \\ \mathrm{IL} & =\text { Interleuquina. } \\ \mathrm{LB} & =\text { Linfocito B. } \\ \mathrm{LT} & =\text { Linfocito T. } \\ \mathrm{NIH} & =\text { National Institute of Health. } \\ \mathrm{PNC} & =\text { Penicilina. } \\ \mathrm{RN} & =\text { Recién nacido. } \\ \mathrm{SNC} & =\text { Sistema nervioso central. } \\ \mathrm{STAT} & =\text { Signal transducer and activator of } \\ & \text { transcription, } \\ \text { Th } & \text { Linfocito T helper, } \\ \text { TYK } & =\text { Tyrosine kinase. } \\ \mathrm{UI} & =\text { Unidades internacionales. } \\ \mathrm{US} & =\text { United States. } \\ \mathrm{VIH} & =\text { Virus inmunodeficiencia humana. } \\ \mathrm{VHS} & =\text { Velocidad de eritrosedimentación. }\end{array}$

\section{Introducción}

En 1966 Davis et al. publicaron los casos clínicos de dos pacientes pelirojas portadoras de un cuadro caracterizado por eczema, infecciones sinopulmonares recurrentes y abscesos estafilocócicos "fríos" denominándolo, síndrome de Job, en alusión al personaje bíblico'.

Posteriormente en 1972 Buckley et al. reportaron la asociación de este cuadro con au- mento de los niveles séricos de inmunoglobulina $\mathrm{E}$ (hiper IgE) y una serie de características fenotípicas, denominándolo síndrome Hiper IgE (SHIGE) ${ }^{2}$.

El SHIGE se clasifica en dos tipos. El tipo I, autosómico dominante (SHIGE-AD), en el cual los pacientes se presentan con anormalidades en distintos sistemas incluyendo el inmunológico, tejido conectivo, esquelético y vascular entre otros, y el tipo II, autosómico recesivo (SHIGE-AR), que también afecta al sistema inmune, manifestado como IgE eleva$\mathrm{da}$, infecciones recurrentes de piel y pulmón, susceptibilidad a infecciones virales como $\mathrm{Mo}$ lluscum contagiosum y compromiso del SNC, pero carece de las alteraciones musculoesqueléticas $^{3-5}$.

La clasificación más reciente del Comité de Expertos de la Unión Internacional de Sociedades de Inmunología, en el grupo de las Inmunodeficiencias primarias (IDP) con síndromes bien definidos incluye al SHIGE-AD, con su denominación original de Síndrome de Job y tres subtipos de SHIGE-AR que no presentan alteraciones esqueléticas ni neumatoceles y que los subdivide en Deficiencia de TYK2, Deficiencia de DOCK8 de acuerdo a su anormalidad molecular y uno de origen desconocido ${ }^{6}$. Existen dos formas de herencia en el SHIGE cuyas principales características se resumen en la tabla 1. Además de las distintas manifestaciones clínicas y más allá de la elevación marcada de la IgE sérica, las dos formas autosómicas del SHIGE difieren en algunas alteraciones de la respuesta inmune. En pacientes con SHIGE$\mathrm{AD}$ se ha descrito disminución de linfocitos (L) Th17, de LB de memoria y de la producción de anticuerpos. Por su parte, en enfermos con SHIGE-AR se ha encontrado defecto en las se- 
Tabla 1. Características clínicas, herencia y defecto molecular en las dos formas autosómicas de SHIGE

\begin{tabular}{|c|c|c|c|}
\hline Enfermedad & Rasgos asociados & Herencia & $\begin{array}{l}\text { Defecto genético/ } \\
\text { patogenia posible }\end{array}$ \\
\hline $\begin{array}{l}\text { SHIGE Autosómico } \\
\text { dominante (S. de Job) }\end{array}$ & $\begin{array}{l}\text { Dismorfia facial, puente nasal ancho, eczema, osteoporosis, } \\
\text { fracturas, escoliosis, retraso recambio dentario, hipermovi- } \\
\text { lidad articular, infecciones bacterianas (cutáneas, abscesos } \\
\text { pulmonares, neumatocele) por } S \text {. aureus, Candidiasis }\end{array}$ & $\begin{array}{l}\text { AD, defecto } \\
\text { de novo } \\
\text { frecuente }\end{array}$ & $\begin{array}{l}\text { Mutación en STAT3 } \\
\text { heterozigota dominante } \\
\text { negativa }\end{array}$ \\
\hline $\begin{array}{l}\text { SHIGE Autosómico } \\
\text { recesivo ( } 3 \text { subgrupos) }\end{array}$ & $\begin{array}{l}\text { Sin alteraciones del tejido conectivo ni esqueleto, sin } \\
\text { neumatocele }\end{array}$ & $A R$ & \\
\hline 1. Deficiencia de TIK2 & $\begin{array}{l}\text { Susceptibilidad a bacterias intracelulares (Micobacterias, } \\
\text { Salmonella), hongos, virus }\end{array}$ & $A R$ & Mutación en TYK2 \\
\hline 2. Deficiencia de DOCK8 & $\begin{array}{l}\text { IRR, infecciones cutáneas extensas por virus y } S \text {. aureus, } \\
\text { mayor riesgo de cáncer, atopia severa, anafilaxia }\end{array}$ & $A R$ & Mutación en DOCK8 \\
\hline 3. Origen desconocido & Hemorragia SNC, infecciones virales y fúngicas & $A R$ & Desconocido \\
\hline
\end{tabular}

$\mathrm{AD}$ = autosómico dominante; $\mathrm{AR}=$ autosómico recesivo; DOCK8 = Dedicator of cytokinesis 8; IRR = infecciones respiratorias recurrentes; SNC = sistema nervioso central; STAT3 = Signal transducer and activator of transcription 3; TYK2 = Tyrosine kinase 2.

ñales de múltiples citoquinas y reducción parcial en los LB circulantes en la deficiencia de DOCK8, y disminución de LT y LB circulantes e IgM baja en la deficiencia de TYK ${ }^{26}$.

SHIGE-AD se define como una inmunodeficiencia primaria caracterizada clínicamente por síntomas de la esfera inmunológica como eczema, infecciones sinopulmonares recurrentes, Hiper IgE y otras alteraciones de la respuesta inmune, asociado a características fenotípicas particulares que comprometen el sistema músculo esquelético, tejido conectivo y vascular ${ }^{3-5}$.

Es una enfermedad infrecuente, de incidencia desconocida, con una relación hombre: mujer de 1:1, que se puede observar en miembros de sucesivas generaciones en una familia y ha sido reportado en varias etnias y razas, sin una predilección clara ${ }^{4-8}$. Según el último reporte publicado por la Sociedad Latinoamericana de Inmunodeficiencias Primarias el año 2006, se habían registrado 11 casos en Chile, con un total de 149 casos en toda Latinoamérica ${ }^{7}$.

Desde el punto de vista inmunológico estos pacientes presentan una disfunción en la respuesta inflamatoria, con acción deficiente frente a agentes infecciosos y una reparación tisular aberrante asociado a incapacidad para elaborar una respuesta Th17 efectiva ${ }^{8-9}$.

El objetivo es presentar los casos de 3 niños con SHIGE, describiendo las características clínicas y exámenes de laboratorio, y hacer una revisión de los aspectos fisiopatológicos, con especial foco en la forma dominante de la enfermedad.

\section{Casos clínicos}

\section{Caso 1}

Varón con antecedentes de lesiones ampollares en cuero cabelludo desde el período neonatal y piodermitis a repetición. Al año y medio de vida ingresó a consultorio de especialidad por piodermia generalizada asociada a cuadro febril con adenopatías y abscesos en muslos. Al examen físico destacaba facies tosca, frente amplia, pliegue infraorbitario, presencia de ojeras, puente nasal bajo e hipertelorismo. Además de lesiones maculopapulares confluentes en cuello y tronco, eczema occipital, placa hipercrómica glúteo genital, otitis externa purulenta. Se trató con antibióticos con buena respuesta pero con persistencia de otorrea purulenta.

El estudio de inmunoglobulinas séricas IgM, IgG, IgA, complemento, quimiotaxis y estallido respiratorio resultó dentro de rangos normales. Destacaba IgE sérica $56.400 \mathrm{UI} / \mathrm{ml}$ (rango normal para la edad 0-90 UI/ml) y eosinofilia. Se diagnosticó SHIGE y se indicó manejo con cotrimoxazol, cetirizina y ácido ascórbico.

A la edad de 2 años 11 meses fue hospitalizado por flegmón genital con buena respuesta a cloxacilina más cefotaxima ev. En controles posteriores evolucionó con prurito, algorra y verrugas vulgares generalizadas de difícil ma- 
nejo. A los 6 años fue nuevamente hospitalizado por impétigo generalizado con cultivo positivo para $S$. aureus y cultivo de secreción ótica positivo para Pseudomona.

\section{Caso 2}

Varón, a los 2 días de vida inició lesiones pustulosas en cara que posteriormente se extendieron a cuero cabelludo y tronco. Presentó adenopatías axilares y cervicales, y la zona de inyección de vacuna BCG evolucionó con ulceración y sobreinfección. A los 2 meses presentó piodermitis tratada con flucloxacilina. Continuó con impétigo recurrente y algorra, con cultivo de lesiones de piel positivo para $S$. aureus sensible a oxacilina. Presentó 2 neumonías (a los 7 y 11 meses de vida) y presentó otitis media aguda (OMA) a los 8 y 13 meses.

Al año de vida fue evaluado en consultorio de inmunología donde destacó frente prominente, puente nasal deprimido, no se palpaban fontanelas, lesiones papuloeritematosas generalizadas que confluían en el tórax, úlcera de $2 \mathrm{~cm}$ en zona de BCG, amígdalas presentes, adenopatías bilaterales cervicales, axilares e inguinales, algorra, roncus bilaterales, retraso del desarrollo psicomotor (deambulación y adquisición de lenguaje retardado, mal rendimiento escolar, asiste a escuela diferencial).

Los exámenes revelaron leucocitosis de $17.600 \mathrm{xmm}^{3}, 25 \%$ de eosinófilos, VHS $12 \mathrm{ml} /$ hr, VIH (-), C3 y C4 normal, IgA normal, IgG e IgM elevadas por sobre 2 DS para la edad, subpoblaciones de linfocitos normales, IgE muy elevada en 2 oportunidades (3.834 UI/ $\mathrm{ml}$ y $15.340 \mathrm{UI} / \mathrm{ml}$ (valor normal para la edad 0-90 UI/ml). Una biopsia de piel mostró infiltrado linfocitario alrededor de vasos capilares dérmicos y leve queratosis concluyendo en perivasculitis linfocítica leve.

Al año de vida se diagnosticó craneosinostosis simple (escafocefalia sin hipertensión endocraneana, no requirió tratamiento quirúrgico) y a los 18 meses se hospitalizó por pleuroneumonia derecha que requirió drenaje pleural, aislándose $S$. pneumoniae resistente a PNC, evolucionó con neumatocele derecho, absceso pulmonar con empiema pleural tabicado e infección de herida en zona del drenaje con cultivo positivo a $S$. aureus. Entre $\operatorname{los} 2$ y 5 años evolucionó con síndrome bronquial obstructivo (SBO) recurrente tratado con corticoides inhalados y broncodilatadores. Continuó con dermatitis persistente con escasa respuesta al tratamiento tópico y lesiones compatibles con onicomicosis en las manos con un micológico directo positivo a levaduras, con Candida, tratado con antimicóticos. A los 6 años presentó neumonía con buena respuesta antibiótica por vía oral. Presentó aumento de volumen cervical derecho $3 \times 4 \mathrm{~cm}$, doloroso, gomoso, fluctuante que se manejó con drenaje y antibioterapia biasociada intravenosa. Se detectó retención de incisivos superiores e inferiores primarios con erupción ectópica de dentición definitiva. Actualmente, a los 7 años, se encuentra en buenas condiciones generales y persiste con algunas lesiones cutáneas e impétigo ocasional en cuero cabelludo.

\section{Caso 3}

Mujer, con antecedentes de dermatitis extensa con compromiso facial y cuero cabelludo desde el período de RN hasta los 2 años que luego se extiendió a tronco y extremidades inferiores, tratada con tópicos y corticoides orales. Desde los 3 años SBO que requirió salbutamol y a los 5 años se agregó corticoides inhalados. A los 6 años hospitalización por neumonía atípica (posible Mycoplasma).

En los exámenes inmunológicos destacó IgE sérica de $4.007 \mathrm{UI} / \mathrm{ml}$, con hemograma e inmunoglobulinas séricas normales. Evolucionó con SBO recurrente, dermatitis atópica y rinitis alérgica por lo que se manejó con antialérgicos, inhaladores y corticoides tópicos. A los 9 años fue operada de quiste tirogloso sin complicaciones y tuvo 1 neumonía de manejo ambulatorio. A los 9 años OMA fue tratada con amoxicilina.

A los 13 años presentó varicela sobreinfectada que dejó lesiones cicatriciales en cara, y acné comedoniano facial.

Hasta la actualidad se controla en forma periódica con niveles de IgE permanentemente sobre $2.000 \mathrm{UI} / \mathrm{ml}$ (rango normal para la edad 0-90 UI/ml), con el resto de inmunoglobulinas normales.

En ninguno de los 3 casos se encontró historia familiar sugerente de SHIGE, y aunque 
Tabla 2. Características más destacadas de los 3 casos presentados

\begin{tabular}{|c|c|c|c|}
\hline & $\begin{array}{c}\text { Caso } \\
1\end{array}$ & $\begin{array}{c}\text { Caso } \\
2\end{array}$ & $\begin{array}{c}\text { Caso } \\
3\end{array}$ \\
\hline Rash período recién nacido & + & + & + \\
\hline Eczema moderado-severo & + & + & + \\
\hline Abscesos & + & + & - \\
\hline Neumonía recurrente & - & + & + \\
\hline Alteraciones pulmonares & - & + & - \\
\hline Otitis Media Aguda & + & + & + \\
\hline Candidiasis mucocutánea & + & + & - \\
\hline Facies característica & + & + & - \\
\hline Retención dentición primaria & - & + & - \\
\hline Craneosinostosis & - & + & - \\
\hline IgE sérica (UI/ml) & 57.700 & 15.340 & 4.007 \\
\hline Eosinofilia & + & + & + \\
\hline
\end{tabular}

tendrían herencia autosómica dominante, es frecuente que el defecto molecular causal ocurra como mutación «de novo» ${ }^{6}$. En la tabla 2 se resumen las características más destacadas de los 3 casos reportados.

\section{Discusión}

Los enfermos presentados cumplen con las manifestaciones y evolución descritas para el SHIGE. En la tabla 3 se muestran las características clínicas, inmunológicas y alteraciones somáticas con los porcentajes estimados de prevalencia de estas alteraciones que se han publicado en este tipo de pacientes ${ }^{3}$.

El eczema, es uno de los síntomas cardinales, y típicamente comienza en las primeras semanas de vida, como se presentó en los 3 pacientes analizados. Reportado hasta en un $18 \%$ al momento de nacer, se manifiesta como rash pápulo pustular, costroso, muy pruriginoso que se inicia en cara, nuca y luego se extiende hasta los glúteos. La biopsia de piel usualmente muestra gran infiltrado eosinofílico y clásicamente el cuadro se ve exacerbado por sobre infección con $S$. aureus ${ }^{8-10}$. Es frecuente la presencia de furúnculos, abscesos y
Tabla 3. Características clínicas descritas en síndrome Hiper IgE

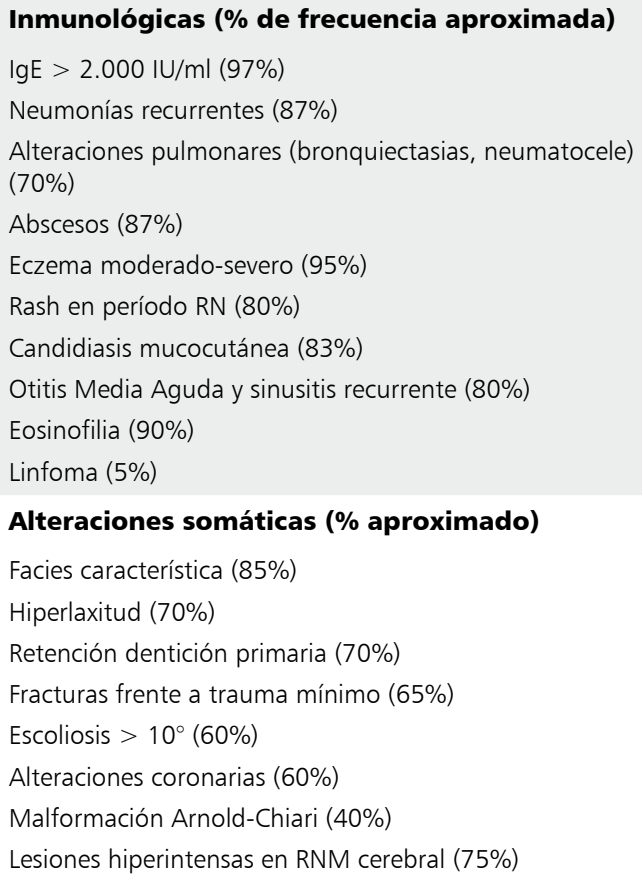

(Adaptado de Freeman A, et al. Pediatr Res. 2009; 65: 32R-37R).

celulitis, complicados ocasionalmente con linfadenitis. Estas lesiones se presentan con una característica casi patognomónica como son abscesos "fríos", es decir carecen de signos inflamatorios como calor o aumento de temperatura, pero al ser drenados contienen gran cantidad de pus ${ }^{8-10}$. En los pacientes varones de esta serie las manifestaciones de piodermitis e infecciones ganglionares fueron notorias.

Las infecciones óticas y sinopulmonares son recurrentes y son producidas clásicamente por $S$. aureus en su mayoría aunque también por Haemophilus influenzae y Streptococcus del grupo A y $\mathrm{B}^{3,8-9}$. Las infecciones pulmonares, a pesar de tratamiento adecuado y oportuno, generan secuelas como bronquiectasias, neumatocele y fístulas, debido a una respuesta inflamatoria y cicatricial aberrante. Secundariamente estas lesiones suelen ser colonizadas por Pseudomona y Aspergillus comportándose desde el punto de vista microbiológico como pacientes portadores de fibrosis quística. Estos gérmenes son capaces de causar infección 
sistémica, una de las causas más importantes de morbimortalidad seguido por la hemoptisis masiva ${ }^{3,8-9}$. Con alguna frecuencia ocurren otras infecciones oportunistas como neumonía por P. jiroveci, Histoplasmosis diseminada $\mathrm{y}$ Criptococcus $^{8}$.

La candidiasis mucocutánea es otra de las infecciones frecuentes, evidenciándose como onicomicosis y onicodistrofia, vaginitis y candidiasis oral a repetición ${ }^{3,8-9}$.

En el estudio inmunológico, destaca elevación de $\operatorname{IgE}$ generalmente mayor a 2.000 $\mathrm{IU} / \mathrm{ml}$. Este valor de corte es arbitrario, y se definió para poder usarlo como criterio diagnóstico, pero al hacer el ajuste por edad, tener 10 veces el valor normal se considera significativo. Existe un porcentaje de recién nacidos con SHIGE que pueden nacer con valores normales de IgE y hasta un $20 \%$ de los adultos llegan a normalizar los valores. Este aumento no es proporcional a la severidad del cuadro y gran porcentaje está dado por IgE específica a $S$. aureus y Candida. Los niveles de IgG, IgA e IgM generalmente se encuentran dentro de rango normal ${ }^{3,8-9}$.

Habitualmente el hemograma no muestra alteraciones, aunque se ha descrito neutropenia relativa ${ }^{3}$. Algunos pacientes muestran eosinofilias relativas de hasta $40-50 \%$ y absolutas mayores a 2DS. Las subpoblaciones linfocitarias se encuentran dentro de rangos normales excepto los LT CD4 y LB de memoria ${ }^{3,11}$. También se ha reportado poca respuesta a vacunas proteicas y de polisacáridos ${ }^{3,8,12}$.

Con respecto a las manifestaciones extra inmunológicas, se describe un fenotipo característico, con una facies que se hace más evidente hacia la adolescencia. Tienen puente y base nasal ancha, protrusión de la frente y leve prognatismo, ojos hundidos, aumento de la distancia inter cantos externos y la piel engrosada con poros dilatados. De las manifestaciones musculoesqueléticas destacan retardo de crecimiento, craneosinostosis, retención de la dentición primaria que puede llevar a la presencia de doble fila de dientes, anomalías en paladar duro y lengua (paladar ojival, depresión central lingual, con fisuras y arrugas de la mucosa oral). La osteopenia y fracturas con trauma mínimo son frecuentes; escoliosis e hiperlaxitud, con enfermedad osteoarticular degenerativa precoz también están dentro de las manifestaciones observadas ${ }^{3,8-9}$.

Un porcentaje puede presentar alteraciones de la vasculatura, manifestándose como aneurismas, pseudoaneurismas y vasculitis, que comprometen principalmente las arterias coronarias, carótidas y arterias cerebrales y se ha reportado incluso casos de infarto agudo al miocardio por ruptura de aneurisma ${ }^{13}$. En la RNM cerebral, no es infrecuente visualizar áreas hiperintensas en T2, sin haberse podido dilucidar el significado clínico de las mis$\operatorname{mas}^{3,4}$.

Al igual que en otras inmunodeficiencias, existe un riesgo aumentado de neoplasias especialmente linfoproliferativas como linfoma No Hodgkin, linfoma de Hodgkin y leucemia, y también se han reportado cáncer de pulmón, hígado y cáncer escamoso de vulva ${ }^{4,8}$. Los pacientes presentados se encuentran en controles periódicos, evaluando eventuales manifestaciones de compromiso vascular cardíaco o neurológico, con educación preventiva a sus familiares.

La patogenia de esta enfermedad se debe a un defecto de la vía de señalización JakSTAT3 ${ }^{3,14-20}$. La mayoría presenta mutaciones dominantes negativas en STAT3, lo que quiere decir que el alelo mutado ejerce un efecto negativo sobre el alelo normal. La mutación homocigota es incompatible con la vida ${ }^{20}$. STAT3 participa en la transducción de señales intracelulares de varias vías inmunológicas, tanto proinflamatorias como antiinflamatorias, explicando las alteraciones a nivel inmunológico y en otra amplia gama de tejidos, produciendo las manifestaciones no inmunológicas ${ }^{14-20}$. Una de las vías clásicamente afectada es la diferenciación de la respuesta inmune hacia un perfil Th17 lo que se traduce en déficit de secreción de interleuquina (IL)-10, IL-17, IL-21, IL-22 e IL-23. La vía Th17 y sus citoquinas son necesarias como mecanismo de defensa contra hongos y bacterias extracelulares, porque modulan el reclutamiento y activación de neutrófilos $y$, por otro lado, estimulan la secreción de péptidos como las beta defensinas, un importante mecanismo de defensa en la piel y sistema respiratorio. Estas alteraciones explican la sus- 
Tabla 4. Sistema de puntaje clínico y de laboratorio del NIH para diagnóstico de S. Hiper IgE

\begin{tabular}{|c|c|c|c|c|c|c|c|c|c|c|}
\hline \multirow[t]{2}{*}{ Hallazgos clínicos } & \multicolumn{10}{|c|}{ Puntaje } \\
\hline & 0 & 1 & 2 & 3 & 4 & 5 & 6 & 7 & 8 & 10 \\
\hline $\begin{array}{l}\text { Nivel más alto de lgE } \\
\text { sérica }(\mathrm{Ul} / \mathrm{mL})\end{array}$ & $<200$ & $\begin{array}{c}200- \\
500\end{array}$ & & & $\begin{array}{l}501- \\
1.000\end{array}$ & & & & $\begin{array}{l}1.001- \\
2.000\end{array}$ & $>2.000$ \\
\hline Abscesos cutáneos & No & & $1-2$ & & $3-4$ & & & & $>4$ & \\
\hline Episodios de neumonía & No & & 1 & & 2 & & 3 & & $>3$ & \\
\hline $\begin{array}{l}\text { Alteraciones parénquima } \\
\text { pulmonar }\end{array}$ & Ausente & & & & & & $\begin{array}{l}\text { Bronquiec- } \\
\text { tasias }\end{array}$ & & $\begin{array}{l}\text { Neuma- } \\
\text { tocele }\end{array}$ & \\
\hline $\begin{array}{l}\text { Retención dientes } \\
\text { primarios }\end{array}$ & No & 1 & 2 & & 3 & & & & 3 & \\
\hline $\begin{array}{l}\text { Escoliosis (ángulo } \\
\text { curvatura máxima) }\end{array}$ & $<10^{\circ}$ & & $10-14^{\circ}$ & & $15-20^{\circ}$ & & & & $>20^{\circ}$ & \\
\hline Fracturas patológicas & No & & & & $1-2$ & & & & $>2$ & \\
\hline $\begin{array}{l}\text { Recuento eosinófilos } \\
\text { (valor más alto } \mathrm{x} \mathrm{mm}^{3} \text { ) }\end{array}$ & $<700$ & & & $700-800$ & & & $>800$ & & & \\
\hline Facies característica & Ausente & & Leve & & & Presente & & & & \\
\hline Anomalías en línea media & Ausente & & & & & Presente & & & & \\
\hline Rash neonatal & Ausente & & & & Presente & & & & & \\
\hline Eczema (peor estado) & Ausente & Leve & Moderado & & Severo & & & & & \\
\hline Número de IRA por año & $1-2$ & 3 & $4-6$ & & $>6$ & & & & & \\
\hline Candidiasis & No & Oral & Uñas & & Sistémica & & & & & \\
\hline Otras infecciones graves & No & & & & Presente & & & & & \\
\hline Infección fatal & Ausente & & & & Presente & & & & & \\
\hline Hiperlaxitud & Ausente & & & & Presente & & & & & \\
\hline Linfoma & Ausente & & & & Presente & & & & & \\
\hline Aumento ancho nasal & $<1 \mathrm{DS}$ & $1-2 D S$ & & & & & & & & \\
\hline Paladar alto & Ausente & & Presente & & & & & & & \\
\hline Corrección por edad & $<5$ años & & & 2-5 años & & $1-2$ años & & $\leq 1$ año & & \\
\hline
\end{tabular}

ceptibilidad de estos pacientes a infecciones por $S$. aureus y Candida ${ }^{21-22}$. No se sabe bien si por defecto o como mecanismo compensatorio existe una desviación de la respuesta inmunológica hacia un perfil Th2 lo que da cuenta de la elevación de IgE y la eosinofilia ${ }^{20}$.

Hasta antes de la posibilidad de estudio genético, el diagnóstico de este síndrome era clínico y el US National Institutes of Health (NIH) propuso una serie de criterios para determinar la probabilidad de diagnóstico y de presentar mutación en STAT3 (tabla 4), estableciendo el diagnóstico como altamente probable si reunía más de 40 puntos, posible entre 20 y 40 puntos e improbable con menos de 20 puntos $^{23}$. Los 3 enfermos presentados sumaron más de 40 puntos en este sistema (45, 63 y 41 respectivamente).

Con la posibilidad de estudio genético, se han propuesto otros sistemas de diagnóstico que considera el nivel de IgE, el recuento de linfocito Th17, cinco características clínicas (neumonías recurrentes, rash en el recién nacido, fracturas patológicas, facies característica, paladar hendido) e historia familiar ${ }^{8,18,19}$. En nuestro medio no es factible realizar estudio de linfocitos Th17 ni análisis molecular para detección de mutación de STAT3 u otros defectos.

Uno de los principales diagnósticos diferenciales lo constituyen los niños atópicos, con dermatitis, rinosinusitis y asma, con los 
cuales comparten características clínicas y de laboratorio, como por ejemplo, las lesiones cutáneas, tendencia a la sobre infección, cuadros rinosinusales y neumonías a repetición o exacerbaciones del asma, asociado a elevaciones de la IgE total y eosinofilia. Las dos entidades se pueden diferenciar por el contexto personal y familiar atópico, la edad de inicio puede ser más tardía, la distribución de lesiones cutáneas y ausencia de las características fenotípicas en los atópicos. Además las infecciones sinopulmonares bacterianas tienen respuesta inflamatoria sistémica asociada y habitualmente con adecuado tratamiento se van a resolver ad-integrum. Un estudio que incluyó 78 enfermos con eczema, IgE elevada e infecciones estafilocócicas reveló que los marcadores más significativos para establecer el diagnóstico diferencial de SHIGE-AD fueron los abscesos internos, infecciones severas, neumatoloceles, fracturas patológicas, escoliosis, score NIH mayor de 40 puntos y candidiasis mucocutánea y ungueal ${ }^{24}$.

Otros diagnósticos diferenciales a destacar son el S. de Wiskott-Aldrich, Inmunodeficiencia combinada severa (S. Omenn) y otras causas de Hiper IgE y/o eosinofilia secundarias ${ }^{4,8}$.

El tratamiento es de soporte y los objetivos son el control de los síntomas, como el prurito y la dermatitis, y prevenir la ocurrencia de enfermedades sistémicas severas ${ }^{4,8}$.

Dentro de los cuidados de la piel destacan la hidratación con cremas emolientes, antihistamínicos, corticoides tópicos de baja potencia por períodos cortos y baños con cloro diluido para bajar la carga bacteriana de la piel, junto con vigilancia y tratamiento de sobreinfecciones ${ }^{4,8}$. El uso de cotrimoxazol profiláctico ha permitido disminuir el número de infecciones rinosinusales y neumonías. También se recomienda la profilaxis de candidiasis recurrente $^{4,8}$. Existen algunos reportes de uso de trasplante de médula con resultados aún no concluyentes. El trasplante de precursores hematopoyéticos puede corregir las alteraciones dependientes de la respuesta inmune anormal pero no soluciona el resto del compromiso esquelético o de otros órganos ${ }^{8}$.

El pronóstico está determinado por las infecciones y sus complicaciones, describiéndose muerte por neumonía, hemoptisis masiva, complicación de neumatocele y secundario a linfoma ${ }^{8}$.

En conclusión, SHIGE-AD es una inmunodeficiencia primaria caracterizada por infecciones cutáneas, ganglionares, óticas y pulmonares, asociada a alteraciones del tejido conectivo, esqueléticas, cerebrales y vasculares. Todas estas alteraciones se explican por la mutación asociada a STAT3. La patogénesis de la inmunodeficiencia reside en una alteración en la vía Th17. Es una patología infrecuente, que requiere alto grado de sospecha siendo importante el manejo precoz de las infecciones que en general presentan escasa respuesta sistémica. Uno de sus principales diagnósticos diferenciales está dado por el niño atópico con infecciones recurrentes pero difieren en el contexto, respuesta y resolución frente a las infecciones y la falta de las otras características fenotípicas.

\section{Referencias}

1. Davis SD, Schaller J, Wedgwood RJ: Job's syndrome. Recurrent, "cold" staphylococcal abscesses. Lancet 1966; 1: 1013-5.

2.- Buckley RH, Wray BB, Belmaker EZ: Extreme hyperimmunoglobulinemia $\mathrm{E}$ and undue susceptibility to infection. Pediatrics 1972; 49: 59-70.

3.- Freeman AF, Holland SM: Clinical manifestations, etiology, and pathogenesis of the Hyper IgE Syndromes. Pediatr Res 2009; 65: 32R-37R.

4.- Sowerwine KJ, Holland SM, Freeman AF: Hyper-IgE syndrome update. Ann N Y Acad Sci 2012; 1250: 25-32.

5.- Freeman AF, Holland SM: The Hyper IgE Syndromes. Immunol Allergy Clin North Am 2008; 28: 277-91.

6.- Al-Herz W, Bousfiha A, Casanova JL, et al: Primary immunodeficiency diseases: an update on the classification from the International Union of Immunological Societies Expert Committee for Primary Immunodeficiency. Frontier Immunol 2011; 2: 54.

7.- Leiva L, Zelasco M, Oleastro M, et al: Primary Immunodeficienncy Diseases in Latin América: The Second Report of the LAGID Registry. J Clin Immunol 2007; 27: 101-8.

8.- La Pine T, Hill H: Hyperimmunoglobulin E síndrome. www.uptodate.com Accessed january 10, 2014.

9.- Freeman AF, Holland SM: Clinical manifestations of hyper IgE syndromes. Disease Markers 2010; 29: 12330 . 
10.- Chamlin SL, McCalmont TH, Cunningham BB, et al. Cutaneous manifestations of hyper-IgE syndrome in infants and children. J Pediatr 2002; 141: 572-5.

11.- Franco J, Moncada M, Velez-Ortega A, et al: Abnormalities in peripheral blood B cells in patients with hyperimmunoglobulinemia E syndrome. Clin Immunol 2008; 127: S71-S71.

12.- Heimall J, Freeman A, Holland S: Pathogenesis of Hyper IgE Syndrome Clinic. Rev Allerg Immunol 2010; 38: $32-8$.

13.- Freeman AF, Avila EM, Shaw PA, et al: Coronary artery abnormalities in hyper-IgE syndrome. J Clin Immunol 2011; 31: 338-45.

14.- Holland SM, De Leo FR, Elloumi HZ, et al: STAT3 mutations in the hyper-IgE syndrome. N Engl J Med 2007; 357: 1608-19.

15.- Minegishi $Y$, Saito M, Tsuchiya S, et al: Dominant negative mutations in the DNA-binding domain of STAT3 cause hyper-IgE syndrome. Nature 2007; 448: 1058-62.

16.- Renner ED, Rylaarsdam S, Anover-Sombke S, et al: Novel signal transducer and activator of transcription 3 (STAT3) mutations, reduced $\mathrm{T}(\mathrm{H}) 17$ cell numbers, and variably defective STAT3 phosphorylation in hyper-IgE syndrome. J Allergy Clin Immunol 2008; 122: 181-7.

17.- Casanova JL, de Beaucoudrey L, Puel A, et al: Mutations in STAT3 and IL12RB1 impair the development of human IL-17-producing T cells. J Exp Med 2008; 205:
1543-50.

18.- Ma CS, Chew GY, Simpson N, et al: Deficiency of Th17 cells in hyper-IgE síndrome due to mutations in STAT3. J Exp Med 2008; 205: 1551-7.

19.- Woellner C, Gertz EM, Schäffer AA, et al: Mutations in STAT3 and diagnostic guidelines for hyper-IgE syndrome. J Allergy Clin Immunol 2010; 125: 424-32.

20.- Minegishi Y, Saito M: Molecular mechanisms of the immunological abnormalities in hyper-IgE syndrome. Ann N Y Acad Sci 2011; 1246: 34-40.

21.- Milner JD, Brenchley JM, Laurence A, et al: Impaired $\mathrm{T}(\mathrm{H}) 17$ cell differentiation in subjects with autosomal dominant hyper-IgE syndrome. Nature 2008; 452: 7736.

22.- Al Khatib S, Keles S, Garcia-Lloret M, et al: Defects along the $\mathrm{T}(\mathrm{H}) 17$ differentiation pathway underlie genetically distinct forms of the hyper IgE syndrome. J Allergy Clin Immunol 2009; 124: 342-8.

23.- US National Institutes of Health. http://www.niaid.nih. gov/LabsAndResources/labs/aboutlabs/lcid/stat3base/ Documents/scoringsystem.pdf Accessed january 10, 2014.

24.- Schimke L, Sawalle-Belohradsky J, Roesler J, et al: Diagnostic approach to the hyper-IgE syndromes: Immunologic and clinical key findings to differentiate hyper-IgE síndromes from atopic dermatitis. J Allergy Clini Immunol 2010; 126: 611-7e. 